\title{
Spatial and temporal variations of small-scale plasma turbulence parameters in the equatorial electrojet: HF and VHF radar observational results
}

\author{
G. Manju, K. S. Viswanathan, and S. Ravindran \\ Space Physics Laboratory, Vikram Sarabhai Space Centre, Trivandrum - 695 022, Kerala, India \\ Received: 14 June 2004 - Revised: 4 March 2005 - Accepted: 14 March 2005 - Published: 3 June 2005
}

\begin{abstract}
The spatial and temporal variations of various parameters associated with plasma wave turbulence in the equatorial electrojet (EEJ) at the magnetic equatorial location of Trivandrum $\left(8.5^{\circ} \mathrm{N}, 77^{\circ} \mathrm{E}\right.$; dip $\left.0.5^{\circ} \mathrm{N}\right)$ are studied for the first time, using co-located $\mathrm{HF}(18 \mathrm{MHz})$ and VHF $(54.95 \mathrm{MHz})$ coherent backscatter radar observations (daytime) in the altitude region of $95-110 \mathrm{~km}$, mostly on magnetically quiet days. The derived turbulence parameters are the mean electron density irregularity strength $(\delta \mathrm{n} / \mathrm{n})$, anomalous electron collision frequency $\left(v_{e}{ }^{*}\right)$ and the corrected east-west electron drift velocity $\left(V_{e y}\right)$. The validity of the derived parameters is confirmed using radar data at two different frequencies and comparing with in-situ measurements. The behaviour of $\delta \mathrm{n} / \mathrm{n}$ in relation to the backscattered power during weak and strong EEJ conditions is also examined to understand the growth and evolution of turbulence in the electrojet.
\end{abstract}

Keywords. Ionosphere (Equatorial ionosphere; Ionospheric irregularities) - Space plasma physics (Turbulence)

\section{Introduction}

The field-aligned ionisation irregularities, namely, the type I and type II irregularities, that are generated by the plasma instabilities in the equatorial electrojet region, have been studied extensively during the past several years using coherent HF and VHF radars (Fejer and Kelley, 1980 and references therein). These (type I and type II irregularities) are generated by the action of the two-stream and gradient drift instability mechanisms, respectively. The type I irregularities are characterized by phase velocities nearly equal to the ionacoustic velocity $\left(\mathrm{C}_{s}\right)$ of the medium and appear more or less simultaneously at all radar elevation angles when the threshold condition is exceeded. For type I waves the observed phase velocity is independent of the zenith angle and for type

Correspondence to: G. Manju

(manju_spl@vssc.org)
II waves, it shows a cosine $\theta$ dependence (where $\theta$ is the elevation angle). Type II irregularities have phase velocities proportional to the electron drift velocity and are observed even for very small electron drifts, whenever the electron density gradient and the electric field are in the same direction.

The characteristic features of the type I and type II irregularities present in the equatorial electrojet (EEJ) are being increasingly understood, due to several theories, both linear and nonlinear, which have been developed, taking into account the effect of plasma wave turbulence (e.g. Sudan, 1983a,b; Farley, 1985; Kudeki et al., 1987). The dominant role of large-scale waves in determining the altitude structure and dynamics of the EEJ was confirmed by the radar interferometry technique (Farley et al., 1981) and later by a combination of ground-based and in-situ measurements (Pfaff et al., 1987). Ronchi et al. (1990, 1991) carried out theoretical investigations on the modifications of large-scale electrojet structure by small-scale plasma wave turbulence. Sudha Ravindran and Reddy (1993) investigated the effect of plasma turbulence on the phase velocity of type I waves from VHF backscatter radar observations.

The high spatial resolution observations of the EEJ at Jicamarca by Farley et al. (1994) have revealed wave-like structures, which are in agreement with the theoretical investigations of Ronchi et al. (1990). The latter included background short wavelength turbulence in the long wavelength equations through a turbulent collision frequency operator and studied its effects on the large-scale dynamics of the EEJ. By this, they could explain the discrepancy between the altitude of the maximum of the experimental and theoretical EEJ current density profiles.

In another approach, Krishna Murthy and Sudha Ravindran (1994) studied experimentally the effect of plasma wave turbulence mainly on the altitude structure of the EEJ, based on limited VHF radar observations at Trivandrum. But the time evolution of the turbulence parameters, their variation in relation to the signal strength; etc have not been examined in their study. In the present study, the parameters 
Table 1. Experimental specifications of VHF and HF radar systems at Trivandrum.

\begin{tabular}{lcc}
\hline Parameter & VHF & HF \\
\hline Operating frequency $(\mathrm{MHz})$ & 54.95 & 18 \\
Pulse width $(\mu \mathrm{s})$ & 20 & 20 \\
Pulse repetition frequency $\left(\mathrm{s}^{-1}\right)$ & 500 & 250 \\
Peak power $(\mathrm{kW})$ & 20 & 50 \\
Average power-aperture product $\left(\mathrm{Wm}^{2}\right)$ & $2.2 \times 10^{5}$ & $1.25 \times 10^{7}$ \\
Beam direction & Fixed beam $30^{\circ}$ & 3 beam orientations zenith, 30 \\
& off zenith towards west & off zenith towards west and east \\
Half power two-way beamwidth $(\mathrm{E}-\mathrm{W})$ & $\sim 3.5^{\circ}$ & $\sim 5^{\circ}$ \\
\hline
\end{tabular}

$\delta \mathrm{n} / \mathrm{n}, v_{e}^{*} / v_{e}$ and $V_{e y}$ (corrected to include turbulence) have been estimated mainly for quiet days at different times, and the time evolution of these parameters has also been studied. These temporal variations are examined in association with the backscatter signal power and $\Delta \mathrm{H}$ variations (deviations of the horizontal component of the Earth's magnetic field from the nighttime level). The behaviour of $\delta \mathrm{n} / \mathrm{n}$ at different altitudes in the EEJ, in relation to the backscattered power during weak and strong EEJ conditions is presented in detail. In addition, the turbulence parameters have been estimated, using both HF and VHF radar observations at several altitudes in the EEJ, for the first time, at Trivandrum on the magnetic equator.

\section{Experimental setup}

The VHF and HF radars at Trivandrum are pulsed, monostatic, coherent, Doppler systems operating in the backscatter mode. The scattered wave vector follows the condition for Bragg scatter, given as

$\lambda=2 \lambda_{i r r} \sin (\theta / 2)$,

where $\lambda$ is the radar wavelength, $\lambda_{i r r}$ is the irregularity scale size and $\theta$ is the scattering angle. For backscattering $\theta=180^{\circ}$; hence,

$\lambda_{i r r}=\lambda / 2$.

These radar systems (used in this study) operate at 54.95 and $18 \mathrm{MHz}$, respectively, corresponding to irregularity scale sizes of 2.7 and $8.3 \mathrm{~m}$ for backscattering. Detailed specifications, data recording and analysis procedures for VHF backscatter radar have been described in Reddy et al. (1987). The mode of data acquisition and analysis procedure is given in Manju (1997) and Janardhanan et al. (2001). The system details for both the radars are given in Table 1 . The parameters estimated from the radar Doppler spectra are the power (zeroth moment), mean Doppler frequency, ${ }_{D}$ (first moment) and the width of the spectrum (second moment). The power is a measure of the strength of the scattering centres present in the volume illuminated by the radar antenna beam; the mean Doppler frequency gives the mean drift velocity of the irregularities and the width of the spectrum is a gross indicator of the strength of turbulence.

HF radar employs the Doppler beam swinging (DBS) technique to point the antenna beam at three angles, viz., vertical and $30^{\circ}$ off zenith in the east and west directions. A single $12 \times 6$ antenna array (12 in the magnetic east-west and 6 in the magnetic north-south direction) is employed for both transmission and reception. A centre-fed dipole of full wavelength is used as the antenna element. The entire array is configured in such a manner that there are six sub arrays and the beam positions at three angles are obtained by proper phasing of these sub arrays. For the present study, data recorded in the west beam position only are used, since the VHF radar beam is along the west at zenith angle $30^{\circ}$.

\section{Data and method of analysis}

The present study is carried out using a database obtained partly using VHF radar observations and partly using simultaneous HF and VHF radar observations during daytime only. Both the radars point towards west and hence they measure in the same volume at the same time (for simultaneous observations using the two radars). Section 4.1 presents the results for those days when VHF radar data sets alone are available. These data sets are obtained at 5-min intervals and six data sets are averaged for each half hour to estimate the turbulence parameters (Krishna Murthy and Ravindran, 1994). For the comparative study using both HF and VHF radar data, presented in Sect. 4.2, thirty data sets at one-minute intervals are averaged for each half hour. The averaging is carried out to minimize the effects of winds in the EEJ region with periods less than $25 \mathrm{~min}$ on the deduced altitude structure of the electrojet.

The radar spectral data used for the present study have been selected so that they are purely type II (uncontaminated by type I). This assures the reliability of electron drift velocity and the electric field derived from the irregularity drift velocity (Viswanathan et al., 1987). This is due to the fact that the phase velocity of type II irregularities is directly related to the electron drift velocity and hence to the driving electric field, whereas the phase velocity of type I waves becomes saturated to the ion-acoustic velocity $\left(\mathrm{C}_{S}\right)$ 
irrespective of the electric field magnitude. Since the generation of type I waves at higher scale sizes is less probable, the HF radar observations are generally free from type I contamination. With the VHF radar observations, significant contribution from type I irregularity is mostly present close to noontime (Viswanathan et al., 1987) in the altitude range of $101-112 \mathrm{~km}$.

The method of estimation of turbulence parameters used here involves the matching of the experimental and theoretical drift velocity profiles of the EEJ by including the turbulence contribution in the drift velocity equations, thereby removing the discrepancy between the altitude of maximum of the two profiles (Krishna Murthy and Ravindran, 1994). The radar signal is required to be present at six or more altitudes without type I contamination, for the estimation of turbulence parameters using this method. This method is evolved based on the theoretical work presented by Ronchi et al. (1990), who suggested that the main features of the largescale observations and the dynamics of EEJ can be successfully explained when the additional electron mobility and diffusion due to background short wavelength plasma turbulence are also considered. The electric fields of the large amplitude short-scale waves perturb the electron orbits randomly, thus causing anomalous diffusion of electrons across the magnetic field. This anomalous electron diffusion is interpreted mathematically as an additional anomalous electron collision frequency $\left(v_{e}^{*}\right)$ over and above the normal collision frequency $\left(v_{e}\right)$. In the above theory the inclusion of a turbulent mobility operator in the equilibrium equation acts as an enhanced collision frequency $\left(v_{e}^{*}\right)$. The Pedersen and Hall mobilities of electrons, $\mu_{P e}$ and $\mu_{H e}$, respectively, are given as

$\mu_{P e}=q_{e} v_{e} / m_{e}\left(\Omega_{e}^{2}+v_{e}^{2}\right)$

$\mu_{H e}=q_{e} \Omega_{e} / m_{e}\left(\Omega_{e}^{2}+v_{e}^{2}\right)$,

where, $q_{e}$ and $m_{e}$ are the electronic charge and mass, respectively, $\Omega_{e}$ is the electron gyrofrequency and $v_{e}$ is the collision frequency of electrons with neutrals.

According to the non-linear short scale turbulence theory of Ronchi et al. (1990), the expressions for the turbulent Pedersen $\left(\mu_{P e}^{*}\right)$ and Hall $\left(\mu_{H e}^{*}\right)$ mobility parameters are given as

$\mu_{P e}^{*}=1 / 2(\Psi / 1+\Psi)\left(\mu_{H e} / \mu_{P e}\right)^{2}\left\langle\left|\frac{\delta n(h)}{n}\right|^{2}\right\rangle \mu_{P e}$

$\mu_{H e}^{*}=1 / 2(\Psi / 1+\Psi)\left\langle\left|\frac{\delta n(h)}{n}\right|^{2}\right\rangle \mu_{H e}$,

where

$\Psi=v_{i} v_{e} / \Omega_{i} \Omega_{e}$,

where $\Omega_{i}$ is the ion gyrofrequency and $v_{i}$ is the collision frequency of ions with neutrals. $\left\langle\left|\frac{\delta n(h)}{n}\right|\right\rangle$ are the small-scale electron density irregularity strength which is altitude dependent. $\delta \mathrm{n}(\mathrm{h})$ are the fluctuations in electron density for smallscales less than $100 \mathrm{~m}$ as a function of altitude $h$, and $n$ is the large-scale electron density. The brackets indicate that the mean of the quantity for a range of shorter scale sizes less than $100 \mathrm{~m}$ is considered.

For a typical value of $\delta \mathrm{n}(\mathrm{h}) / \mathrm{n}(\sim 10 \%)$ (Pfaff et al., 1987), it is seen that $\mu_{H e}^{*} \ll \mu_{H e}$ and $\mu_{P e}^{*} \geq \mu_{P e}$. Therefore, $\mu_{P e}^{*}$ is the turbulent mobility parameter of interest in the present study.

$V_{e y}$, the experimentally observed electron drift velocity in the E-W direction, is given by (Reddy et al., 1987):

$V_{e y}=V_{p}(1+\Psi)$,

where $V_{p}$ is the phase velocity of type II irregularities in the $\mathrm{E}-\mathrm{W}$ direction.

$\underset{p}{V}=\underset{D}{\lambda}=\underset{D}{5.4 \bar{f}}$ (Reddy et al., 1987),

where ${ }_{D} \bar{f}$ is the mean Doppler frequency and $\lambda$ is the radar wavelength.

The expression for the theoretical electron drift velocity $\left(V_{e y}\right)_{T}$ (Reddy et al ., 1987) is given by

$\left(V_{e y}\right)_{T=}\left[\rho_{i} /(1+\Psi)\right]\left[E_{y} / B\right]$,

where $E_{y}$ is the global E-W electric field and $B$ is the geomagnetic field.

$\rho_{i}=\left(v_{i} / \Omega_{i}\right)$

Here the estimation of turbulence parameters is based on the assumption that the discrepancy between the observed and theoretical electron drift velocity profiles in the EEJ, is due to the non-inclusion of the effect of plasma wave turbulence, in the respective equations (for details, refer to Krishna Murthy and Ravindran, 1994). This is taken care of by including height dependent $\Psi^{*}$ in the equations for $V_{e y}$ and $\left(V_{e y}\right)_{T}$ and equating them.

$V_{e y}=V_{p}\left(1+\Psi+\Psi^{*}\right)$

$\left(V_{e y}\right)_{T}=\left[\rho_{i} /\left(1+\Psi+\Psi^{*}\right)\right]\left(E_{y} / B\right)$.

From Eq. (5),

$$
\begin{aligned}
& \left(v_{e}^{*} / v_{e}\right) \sim \mu_{P e}^{*} / \mu_{P e}=1 / 2(\Psi / 1+\Psi)\left(\mu_{H e} / \mu_{P e}\right)^{2} \\
& \left\langle\left|\frac{\delta n(h)}{n}\right|^{2}\right\rangle
\end{aligned}
$$

where $\left\langle\left|\frac{\delta n(h)}{n}\right|^{2}\right\rangle$ is assumed to be a second degree polynomial in height of the form $\mathrm{a}+\mathrm{bh}+\mathrm{ch}^{2}, \mathrm{~h}$ is the altitude and $\mathrm{a}$, $\mathrm{b}, \mathrm{c}$ are constants to be determined.

$$
\begin{aligned}
& \left(v_{e}^{*} / \nu_{e}\right) \sim \mu_{P e}^{*} / \mu_{P e}=\left(\Psi^{*} / \Psi\right)=1 / 2(\Psi / 1+\Psi) \\
& \left(\mu_{H e} / \mu_{P e}\right)^{2}\left(a+b h+c h^{2}\right) \\
& \Psi^{*}=A\left(a+b h+c h^{2}\right),
\end{aligned}
$$




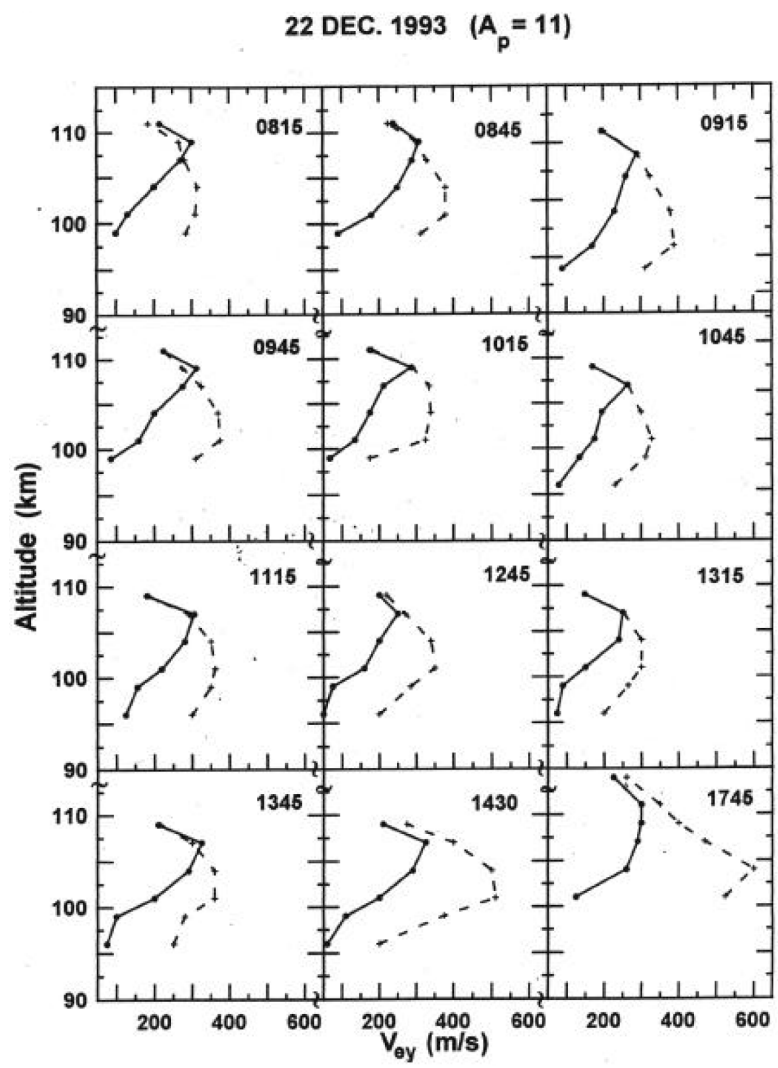

Fig. 1. Daytime altitude profiles of $V_{e y}$ on 22 December 1993. The solid curves correspond to the uncorrected $V_{\text {ey }}$ values (without including turbulence effects), while the dashed curves represent the corrected $V_{e y}$ values obtained after including the effects of turbulence.

where,

$A=1 / 2\left[\Psi^{2} /(1+\Psi)\right]\left(\mu_{H e} / \mu_{P e}\right)^{2}$,

$A$ is calculated at different heights using values obtained from MSIS 86 (Hedin, 1987) model for neutral densities and temperatures.

Equating (12) and (13) and substituting for $\Psi^{*}$ results in

$V_{p}=\rho_{i} /\left[1+\Psi+A\left(a+b h+c h^{2}\right)\right]^{2}\left[E_{y} / B\right]$.

Taking the ratio of $V_{p}$ (at 2 altitudes) for 3 sets of data at six altitudes, $E_{y}$ is eliminated and the equations are solved to obtain the values of a, b and c. Thereafter, the values of $E_{y}, V_{e y}$ (with turbulence parameter $\Psi^{*}$ ), $v_{e}^{*}$ and $\delta \mathrm{n} / \mathrm{n}$ are estimated.

The spatial and temporal variations of the parameters such as $V_{e y}$ (including $\Psi^{*}$ ) and $\delta \mathrm{n} / \mathrm{n}$ (obtained using the above method) are presented in Sect. 4. The behaviour of $\delta \mathrm{n} / \mathrm{n}$ viza-viz the backscattered power is also investigated.

\section{Results}

The data used in the present study are relatively free from contamination by type I irregularities, in view of the fact that winter and summer months have been selected. It should be mentioned here that based on our experience with VHF radar observations, it is known that for low solar activity conditions during winter and summer months, the type I contamination is at a minimum (for details, refer to Vikramkumar et al., 1984). The days selected are relatively magnetically quiet (as is evidenced by the geo-magnetic indices), except for 21 December $1993\left(A_{p}=20\right)$, which is somewhat disturbed. On 21 December 1993, type I contamination is present in the Doppler spectrum between 09:15 and 10:45 IST (Indian Standard Time corresponding to $82.5^{\circ} \mathrm{E}$ longitude leads UT by $5.5 \mathrm{~h}$ ). All times given here correspond to IST. On 15 June $1995\left(A_{p}=6\right)$ data are available during 08:30-16:30, with type I contamination from 10:00-12:00. Hence, turbulence parameters are not estimated during the 10:00-12:00 period. The results presented for 22 December 1993 and 15 June 1995 are obtained using VHF radar observations while those presented for 25 and 26 October, 1995 (equinoctial period) are based on simultaneous HF radar and VHF radar observations.

\subsection{Altitude profiles of $V_{e y}$ and $\delta \mathrm{n} / \mathrm{n}$ in the EEJ - VHF radar observations}

As an example, Fig. 1 shows $V_{e y}$ profiles for the daytime on 22 December $1993\left(A_{p}=11\right)$, which is a relatively magnetically quiet day without type I presence, even at higher altitudes. Hence, data were available at the required six altitudes for estimating turbulence parameters reasonably well. As mentioned earlier, the profiles shown here are the average profiles obtained mostly at each half hour. The solid curves correspond to the deduced $V_{e y}$ profiles without turbulence effects, while the dashed curves correspond to the corrected $V_{e y}$ profiles obtained after including the effects of turbulence. The time in hours corresponding to each panel is given at the top.

It is seen from Fig. 1 that in all cases the altitude of the maximum of the corrected profile is lower than the deduced profile (without turbulence effects). Also, it should be mentioned that the theoretical $V_{e y}$ profile (without considering the effect of turbulence) peaks around $97 \mathrm{~km}$ (not shown in the figure) (Richmond 1973a,b), which is lower than the corrected profile. Thus, the effect of including $v_{e}{ }^{*}$ is to shift the peak of the theoretical profile to a higher level. As can be seen, the magnitudes of the corrected $V_{e y}$ are larger than the deduced values (without turbulence effects), especially below and around the altitude of maximum $V_{e y}$. This is due to the inclusion of $\Psi^{*}$ for the corrected profile. However, the $V_{e y}$ values (including turbulence) are larger mostly in the late afternoon hours in comparison with those in the pre-noon hours, indicating an increase in turbulence strength from prenoon to afternoon.

The altitude profiles of $\delta \mathrm{n} / \mathrm{n}$ obtained, which is directly related to $\Psi^{*}$, refer to Eq. (16), corresponding to these times are shown in Fig. 2. The value is less than $6 \%$ up to $13: 45$ but later increases to $\sim 10 \%$. It is seen that on occasions, it spans a very narrow range and at other times it shows marked altitude variations. Figure 3 shows the altitude profiles of $V_{e y}$ 


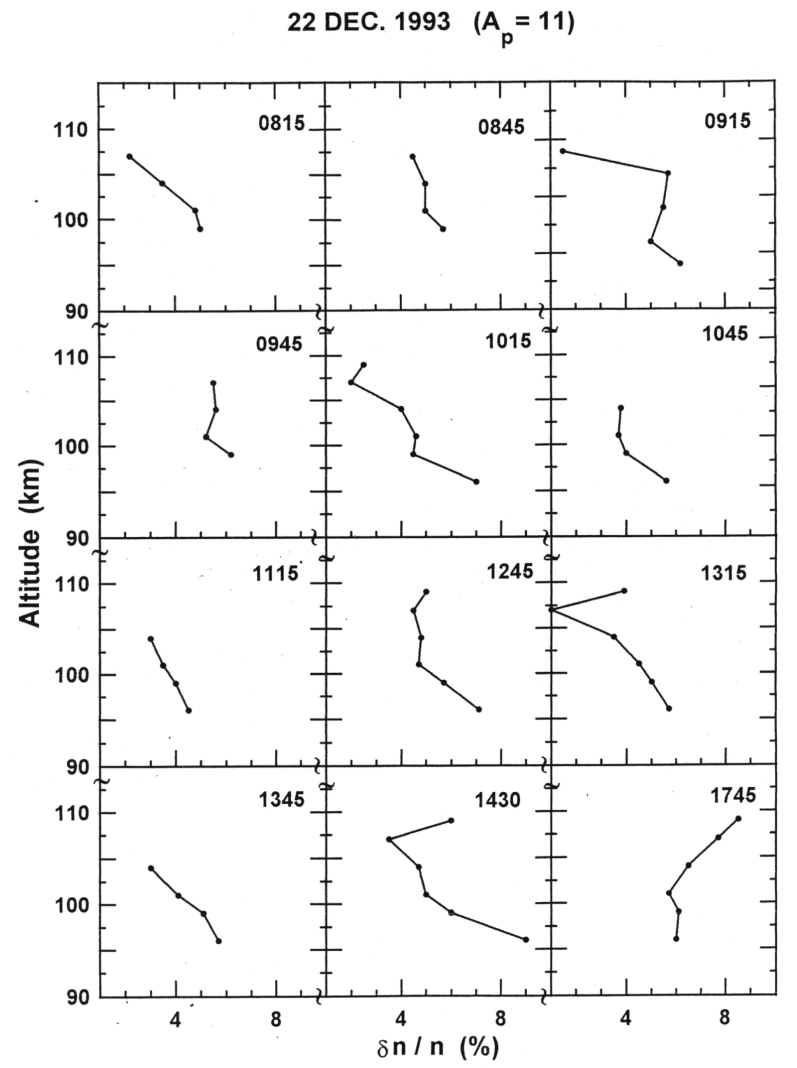

Fig. 2. Deduced altitude profiles of $\delta \mathrm{n} / \mathrm{n}$ corresponding to the times shown in Fig. 1.

(deduced without $\Psi^{*}$ and corrected with $\Psi^{*}$ ) and $\delta \mathrm{n} / \mathrm{n}$ in the left and right panels, respectively, for the pre-noon, close to noon and afternoon times, of 15 June 1995. In Fig. 3, the $V_{e y}$ profiles exhibit similar behaviour as in Fig. 1. The $\delta \mathrm{n} / \mathrm{n}$ values are found to lie in the range of 2-6\% for the pre-noon and noon times with higher values at 15:45. This pattern of variation in $\delta \mathrm{n} / \mathrm{n}$ is seen for all the days examined. There is a consistent increase in $\delta \mathrm{n} / \mathrm{n}$ in all cases during the late afternoon hours.

\subsection{Comparison of turbulence parameters estimated from HF and VHF radar observations}

We have operated the HF and VHF radars simultaneously on a number of days and compared the turbulence parameters estimated from the two sets of observations. Figure 4 shows the altitude profiles of $v_{e}^{*} / v_{e}, \delta \mathrm{n} / \mathrm{n}, \mathrm{V}_{e y}$ and relative power at 11:15 on 25 October 1995. The solid line corresponds to the parameters estimated from the HF radar observations and the broken line to those from VHF radar observations. It is seen that there is a good agreement between the values estimated from the two radars, though VHF radar is sensitive to $2.7-\mathrm{m}$ scale size irregularities while HF radar returns are from $8.3-\mathrm{m}$ scale size irregularities. The $\delta \mathrm{n} / \mathrm{n}$ values are in the range of $2-4 \%$. The $\delta \mathrm{n} / \mathrm{n}$ values are nearly the same for the two radars, although the scale sizes probed are different.

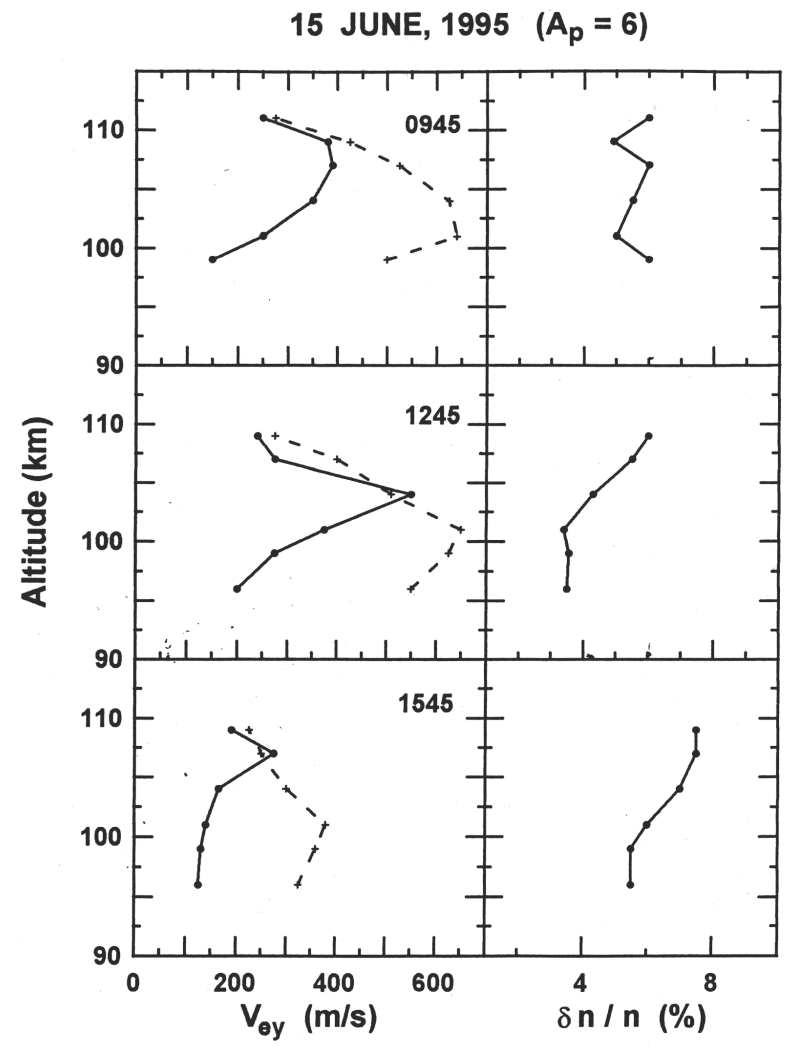

Fig. 3. Uncorrected (solid) and corrected (dashed) altitude profiles of $V_{e y}$ and $\delta \mathrm{n} / \mathrm{n}$ for the pre-noon, close to noon and afternoon on 15 June 1995.

The relative power and $V_{e y}$ are seen to peak at $101 \mathrm{~km}$ in both cases, though the magnitudes differ slightly.

\subsection{Time variation of different turbulence parameters - VHF and HF radar observations}

First we present the observations for 22 December 1993 and 15 June 1995, based on VHF radar observations. Figure 5 shows the time variation of corrected $V_{e y}$, relative power, $\delta \mathrm{n} / \mathrm{n}$ (at $104 \mathrm{~km}$, close to the peak altitude of EEJ) and $\Delta \mathrm{H}$ at Trivandrum for 22 December 1993 from 08:00-18:00. The relative power is obtained from the backscatter signal power of the Doppler spectrum for a given range bin. It is seen from the figure that $V_{e y}$ and the relative power show an increase from $\sim 14: 00$ and reach their maxima around 16:00. Correspondingly the $\delta \mathrm{n} / \mathrm{n}$ values also increase from 3-6\% and continue to increase beyond 16:00. A similar pattern is obtained at other altitudes, too. The $\Delta \mathrm{H}$ values at Trivandrum, shown in the top panel, also reveal a significant increase during this period and thereafter a decrease to near zero by 18:00. The increase in $\Delta \mathrm{H}$ around $16: 00$ is in contrast to the typical $\Delta \mathrm{H}$ variations observed on a quiet day, where the peak value is attained close to noon.

The temporal variations of the estimated east-west electric field $E_{y}$ (taking into consideration $v_{e}^{*}$ ) on this day are shown in Fig. 6. The values increase sharply between 14:00 


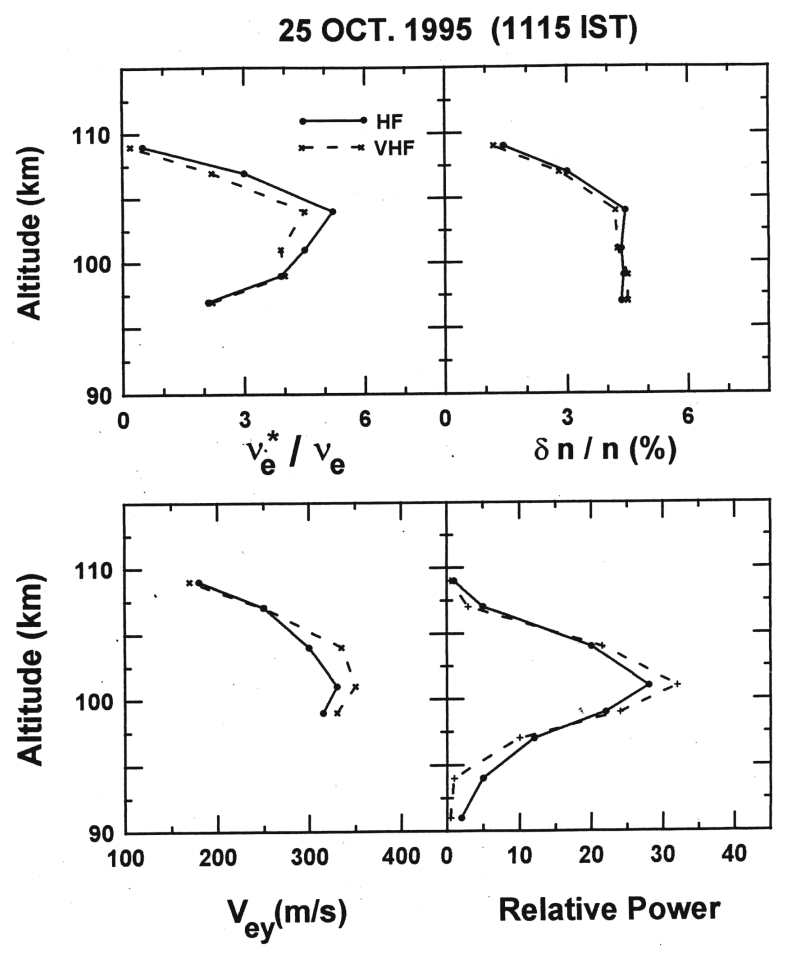

Fig. 4. Altitude profiles of $v_{e}^{*} / v_{e}, \delta \mathrm{n} / \mathrm{n}$, corrected $\mathrm{V}_{e y}$ and relative power (in arbitrary units) corresponding to $11: 15$ on 25 October 1995, from HF and VHF radar observations.

and 16:00, attaining a peak value of $\sim 2.6 \mathrm{mV} / \mathrm{m}$ at 16:00. The height integrated Cowling conductivity $\Sigma_{3}$ generally decreases during the afternoon hours. It is known that $\Delta \mathrm{H}$ is a function of $\Sigma_{3}$ and $\mathrm{E}_{y}$, and hence the observed increase in $\Delta \mathrm{H}$ may quite reasonably be attributed to the large magnitude of $E_{y}$. Another important aspect is that after 16:00, $V_{e y}$, relative power and $\Delta \mathrm{H}$ values decrease, while $\delta \mathrm{n} / \mathrm{n}$ continues to increase to a value of $\sim 8 \%$ at 18:00.

The time variations of these parameters at $99 \mathrm{~km}$ for the same day are shown in Fig. 7. It is seen that in the postnoon period, the power decreases from 13:00 onwards up to $17: 45$. However, $V_{e y}$ increases up to $15: 45$ and then decreases. Thus, on this day $\delta \mathrm{n} / \mathrm{n}$ values are also the relatively high, mostly independent of the variations in $V_{e y}$ and power in the late afternoon and pre-noon hours. Similar is the case at 101 and $107 \mathrm{~km}$. The time variations of $V_{e y}$, relative power, $\delta \mathrm{n} / \mathrm{n}$ (for $104 \mathrm{~km}$ ) and $\Delta \mathrm{H}$ for 15 June 1995 are shown in Fig. 8. The gap in the figure corresponds to the presence of type I in the radar spectrum. It is seen that $\delta \mathrm{n} / \mathrm{n}$ values show similar variations, as shown by $V_{e y}$ and power from 12:45 to 13:45. Beyond 13:45, power and $V_{e y}$ decrease, while $\delta \mathrm{n} / \mathrm{n}$ shows an increase from $\sim 6 \%$ to $8 \%$ by $16: 30$. $\Delta \mathrm{H}$ values do show similar variations with $V_{e y}$ and $\delta \mathrm{n} / \mathrm{n}$, especially when EEJ is strong. Again it is seen that in the pre-noon time the $\delta \mathrm{n} / \mathrm{n}$ values are high while the power and $V_{e y}$ have not yet built up.

Time variations of $V_{e y}$, relative power, $\delta \mathrm{n} / \mathrm{n}$ (all obtained from $\mathrm{HF}$ radar observations) and $\Delta \mathrm{H}$ for 25 and 26 October

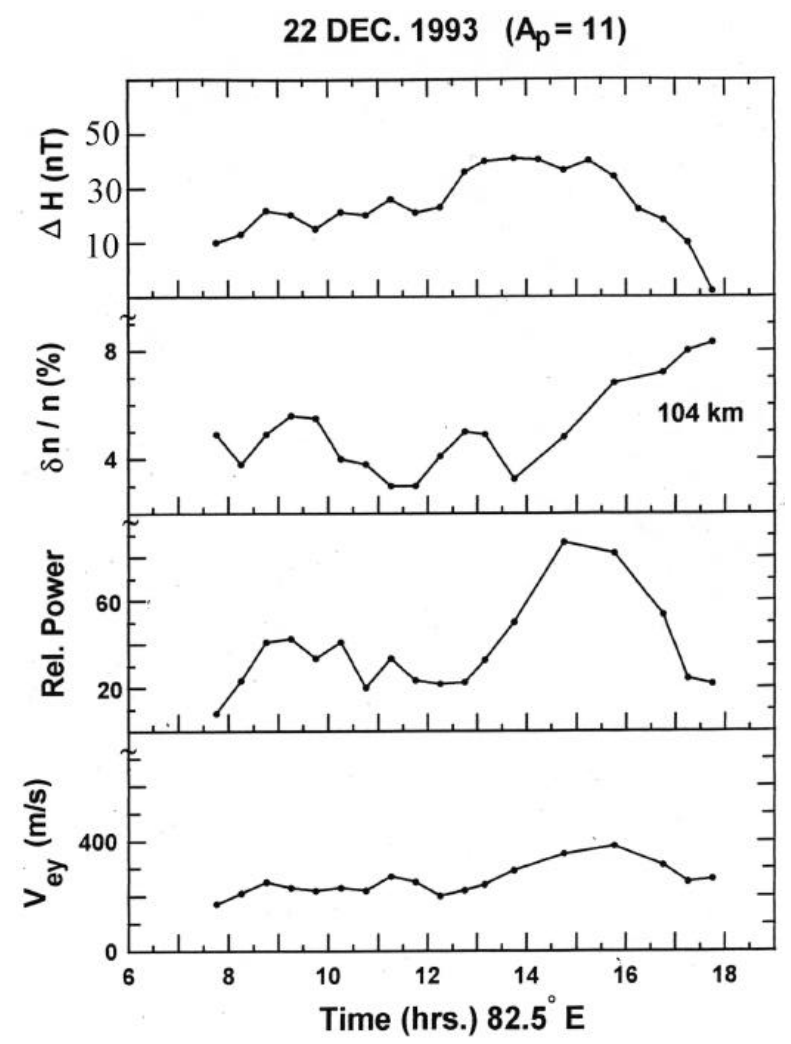

Fig. 5. Daytime variation of corrected $V_{e y}$, relative power, $\delta \mathrm{n} / \mathrm{n}$ at $104 \mathrm{~km}$ and $\Delta \mathrm{H}$ at Trivandrum on 22 December 1993.

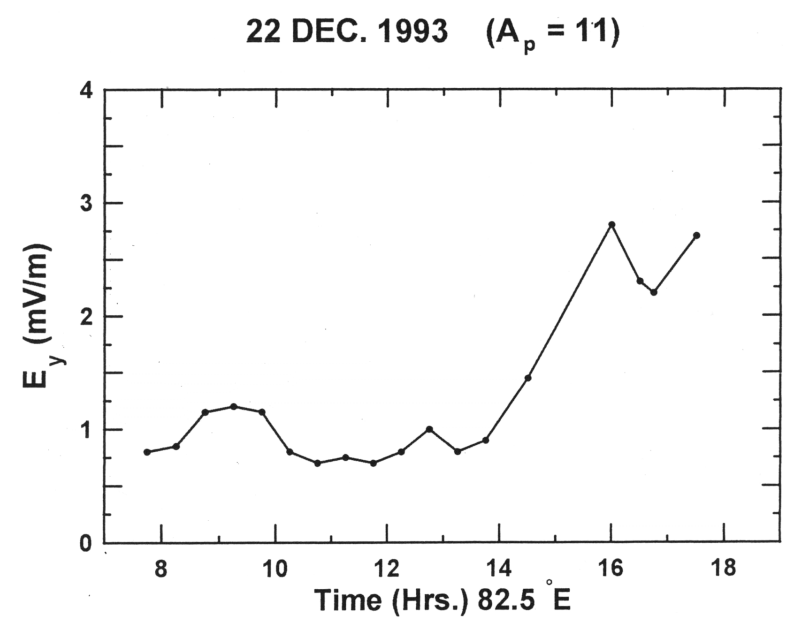

Fig. 6. Daytime variation of the estimated $E_{y}$ (taking into account $\left.v_{e}^{*}\right)$ on 22 December 1993. The sharp increase in the electric field magnitude between 14:00 and 16:00 is to be noted in particular.

1995 are shown in Figs. 9 and 10, respectively. In Fig. 9, $\Delta \mathrm{H}$ values attain their peak at $\sim 10: 30$, nearly close to the time of maximum in $V_{e y}$ (this feature can also be noticed in Fig. 10 for 26 October 1995). Prior to 09:00, the relative power is less, even while $\delta \mathrm{n} / \mathrm{n}$ values are relatively high. Similarly we see high $\delta \mathrm{n} / \mathrm{n}$ values in the late afternoon hours, while the power and $V_{e y}$ are low or decreasing. This behaviour in 
22 DEC. $1993\left(A_{p}=11\right)$

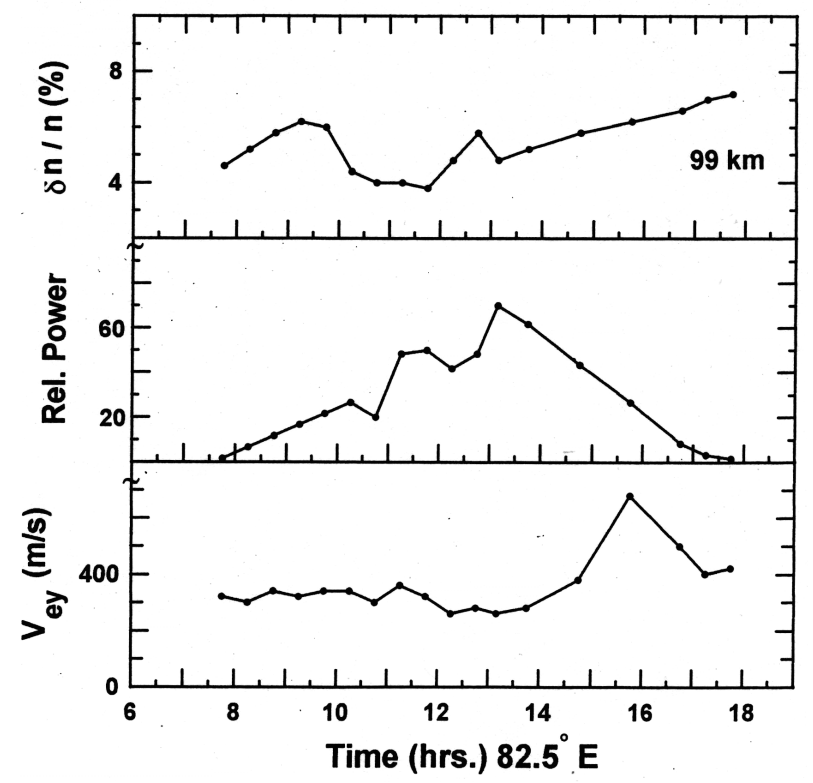

Fig. 7. Daytime variation of corrected $V_{e y}$, relative power and $\delta \mathrm{n} / \mathrm{n}$ at $99 \mathrm{~km}$ on 22 December 1993.

15 JUNE $1995 \quad\left(A_{p}=6\right)$

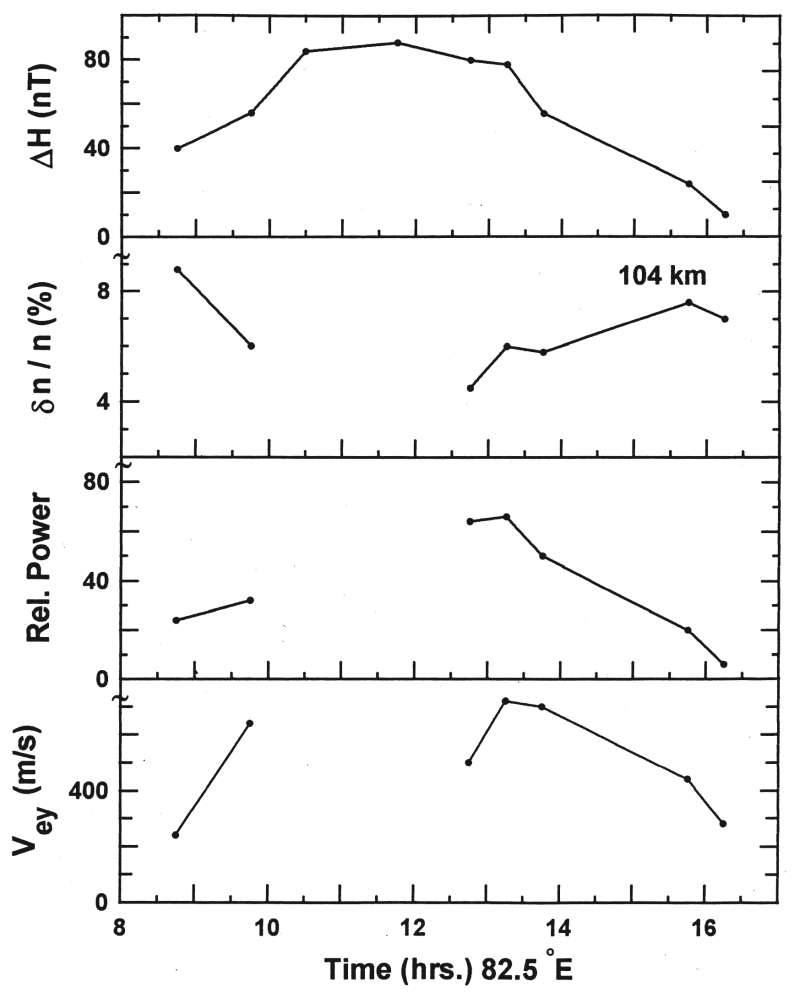

Fig. 8. Same as Fig. 5, but for 15 June 1995.

the pre-noon and post-noon periods is a consistent feature for all the days examined. It is to be noted from Fig. 10 that the parameters $V_{e y}$ and $\delta \mathrm{n} / \mathrm{n}$ are shown only from 11:15, in

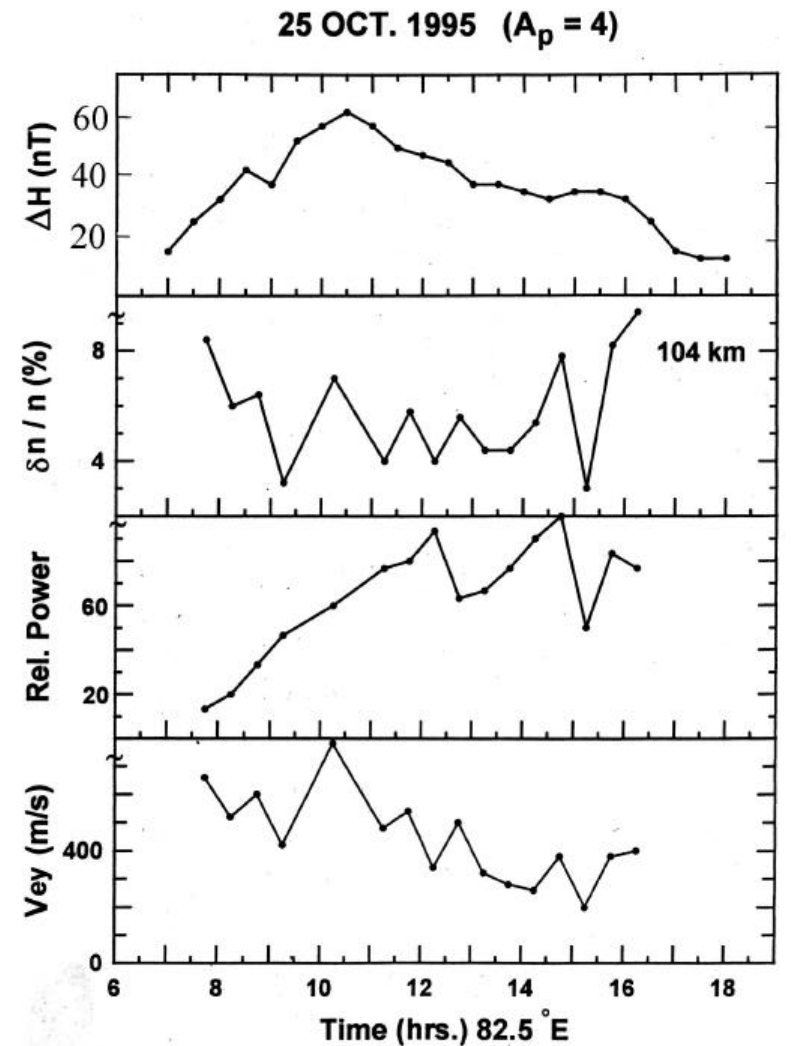

Fig. 9. Same as Fig. 5, but for 25 October 1995.

view of the fact that slight type I contamination was present in the HF radar data prior to that time. In such cases, the data give rise to unrealistically high values of $V_{e y}, \delta \mathrm{n} / \mathrm{n}$ and $v_{e}^{*} / v_{e}$. Further, in Fig. 10, the parameters $V_{e y}$, power, $\delta \mathrm{n} / \mathrm{n}$ and $\Delta \mathrm{H}$ show similar variations up to $\sim 13: 30$. Beyond that time, $\delta \mathrm{n} / \mathrm{n}$ shows an increase, while $V_{e y}$ and power show a decreasing trend. The importance and the implications of the above observations are discussed below.

\section{Discussion}

In the present study, the parameters $\delta \mathrm{n} / \mathrm{n}, v_{e}^{*} / v_{e}$ and $V_{e y}$ (corrected to include turbulence) have been estimated mainly for quiet days at different times. The method of deducing these parameters used in the present study is based on the nonlinear short scale turbulence theory developed by Ronchi et al. (1990) for scale sizes $<100 \mathrm{~m}$ and hence the values deduced using this method correspond to a range of turbulent scale sizes below $100 \mathrm{~m}$. The deduced $\delta \mathrm{n} / \mathrm{n}$ values using both $\mathrm{HF}$ and VHF radars lie in the range of $0-10 \%$. For similar scale sizes Pfaff et al. (1987) have reported $\delta \mathrm{n} / \mathrm{n}$ values in the range $0-10 \%$ using in-situ measurements in Peru for electrojet altitudes. Prakash et al. (1972) have shown using in-situ rocket measurements at Trivandrum that irregularity amplitudes for scale sizes $<15 \mathrm{~m}$ are $0-2 \%$ while that for scale sizes in the range $30-300 \mathrm{~m}$ are $0-20 \%$ for electrojet altitudes. Thus, the values deduced in the present study seem to 


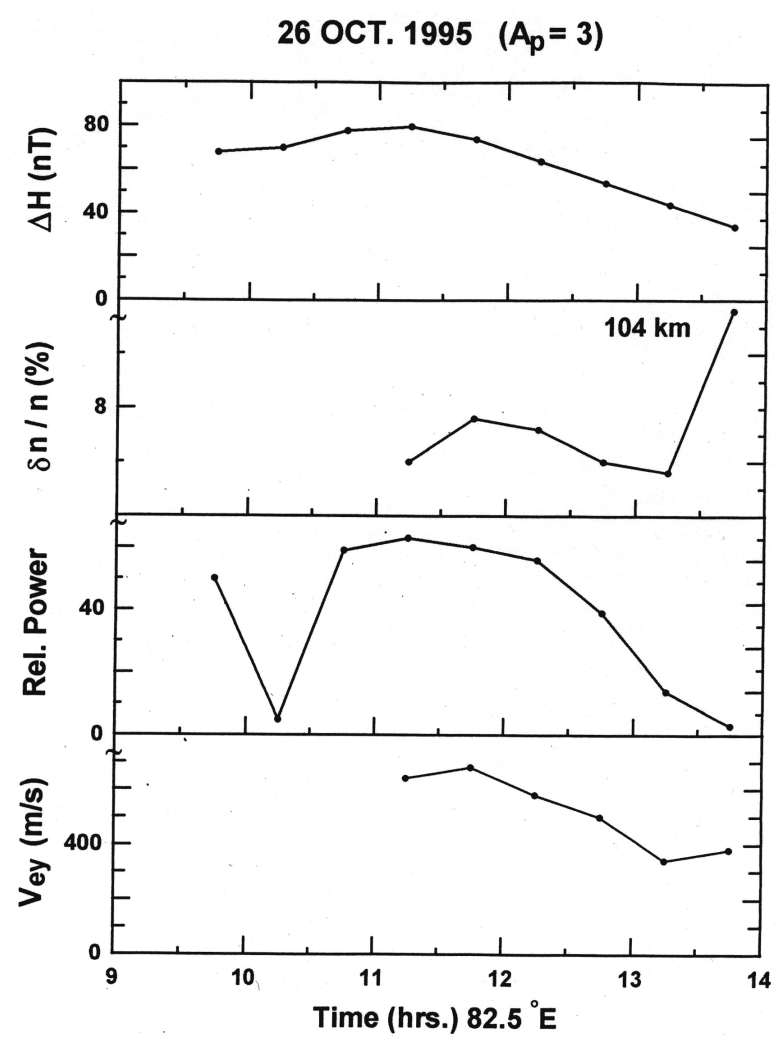

Fig. 10. Same as Fig. 5, but for 26 October 1995.

agree well with different in-situ measurements, as the scale sizes probed by the VHF and HF radars are $2.7 \mathrm{~m}$ and $8.3 \mathrm{~m}$, respectively.

The use of HF radar data, in addition to VHF radar data for estimating turbulence parameters yields $\delta \mathrm{n} / \mathrm{n}$ values in the same range, thereby further confirming the validity of the method used in the present study. Moreover, the approach of using HF and VHF radar observations has an added advantage that VHF radar data is contaminated by the presence of type I irregularities during strong electrojet times (Vikramkumar et al., 1984), whereas during such times turbulence parameters can be estimated from HF radar data, as it is less susceptible to type I contamination.

The phase velocity of type II irregularities, which indicates the strength of the electrojet current, is proportional to the radar measured mean Doppler frequency $\underset{D}{(\bar{f})}$, as mentioned earlier (Reddy et al., 1987). Vikramkumar et al. (1984) have presented the typical daytime variation of the radar measured mean Doppler frequency. They have shown that the electrojet current and signal strength (power) show a rapid increase in the morning (building-up phase), a broad maximum around 11:00 (strong EEJ phase), and a decrease in the afternoon hours (decaying phase). The present study shows that there is a direct relation between $\delta \mathrm{n} / \mathrm{n}$ and power when the EEJ is strong. During those times when the EEJ is building up (before 09:30) and decaying (after 13:30) the $\delta \mathrm{n} / \mathrm{n}$ values are high, while the radar-observed backscattered power is low. During such times (morning building up and afternoon falling off times of the EEJ), the background electron density (n) values are relatively low. These low $\mathrm{n}$ values result in an increase in $\delta \mathrm{n} / \mathrm{n}$ for a given $\delta \mathrm{n}$ value. This could possibly explain the high $\delta \mathrm{n} / \mathrm{n}$ observed during weak EEJ times. Moreover, the backscattered power variations obtained using the VHF radar correspond to irregularities in the wavelength range of $\sim 3 \mathrm{~m}$. During non-steady states of the EEJ, probably energy has not been fully transferred to the very smallscale sizes of $\sim 3 \mathrm{~m}$ from relatively larger scale sizes. This can also result in high $\delta \mathrm{n} / \mathrm{n}$ (which corresponds to all scale sizes below $100 \mathrm{~m}$ ) while power (corresponding to $3 \mathrm{~m}$ scale) is low. When the EEJ gains strength, energy fully reaches the lowest of scale sizes "seen" by the radar and observed power becomes high. As the EEJ gains strength by about 09:30 the background electron density (n) increases and $\delta \mathrm{n} / \mathrm{n}$ values reduce with respect to the earlier values.

\section{Conclusions}

The study carried out using co-located HF and VHF radar observations at Trivandrum brings out the following aspects.

1. The deduced values of $\delta \mathrm{n} / \mathrm{n}$ agree well with the values obtained by other workers using in-situ observations.

2. The $\delta \mathrm{n} / \mathrm{n}$ values obtained using simultaneous $\mathrm{HF}$ and VHF radar observations lie in the same range, thus validating the present method of estimation of turbulence parameters.

3. A direct relationship is observed between $\delta \mathrm{n} / \mathrm{n}$ and backscattered power during strong EEJ times. During building up and decaying phases of EEJ, the $\delta \mathrm{n} / \mathrm{n}$ values are high while the power is low. This shows that during the strong phase of the EEJ energy is carried to the lowest of scale sizes. During the weaker phases of the EEJ, the power values are low while $\delta \mathrm{n} / \mathrm{n}$ is high, as the energy has not been carried to the lowest of scale sizes and a steady state has not been reached. Thus, the comparison of $\delta \mathrm{n} / \mathrm{n}$ and backscattered power sheds light on the growth and evolution of turbulence in the electrojet plasma.

4. The absence of type I contamination in the HF radar data facilitates the estimation of turbulence parameters even when VHF radar data is contaminated by type I irregularities.

The study brings out the utility of the present method in estimating plasma turbulence parameters using HF and VHF radar data. Further, the behavior of $\delta \mathrm{n} / \mathrm{n}$ and backscattered power at different times of the day shows the diurnal evolution of plasma turbulence in the EEJ. This aspect can in the future be studied further to understand the differences in the growth and development of plasma turbulence under different geophysical conditions, such as magnetically highly disturbed, moderately disturbed, and quiet times. Another aspect that can be pursued is the study of the seasonal variations 
of the plasma turbulence parameters, if any. The database generated from such studies can be potentially used to improve existing electrojet models.

Acknowledgements. The authors thank the referees for their valuable comments which helped to improve the paper substantially. The useful discussions with colleagues in Space Physics Laboratory are greatfully acknowledged.

Topical Editor U.-P. Hoppe thanks G. Hassenpflug and T. Blix for their help in evaluating this paper.

\section{References}

Farley, D. T., Ierkic, W. M., and Fejer, B, G.: Radar Interferometry: A new technique for studying plasma turbulence in the ionosphere. J. Geophys. Res., 86, 1467-1472, 1981.

Farley, D. T.: Theory of equatorial electrojet plasma waves: New developments and current status. J. Atmos. and Terr. Phys., 47, 729-744, 1985.

Farley, D. T., Swartz, W. E., Hysell, D. L., and Ronchi, C.: Highresolution radar observations of daytime kilometre scale wave structures in the equatorial electrojet. J. Geophys. Res., 99, 299307, 1994.

Fejer, B. G. and Kelley, M. C.: Ionospheric irregularities. Reviews of Geophys. and Space Phys., 18, 401-454, 1980.

Hedin, A. E.: MSIS-86 thermospheric model. J. Geophys. Res., 92, 4649-4662, 1987.

Janardhanan, K. V., Ramakrishna Rao, D., Viswanathan, K. S., Krishna Murthy, B. V., Shenoy, K. S. V., Mohan Kumar, S. V., Kamath, K. P., Mukundan, K. K., Sajitha, G., Shajahan M., and Ayyappan, C.: HF backscatter radar at the magnetic equator: System details and preliminary results. Indian J. Radio and Space Phys., 30, 77-82, 2001.

Krishna Murthy, B. V. and Sudha R.: Effect of small-scale plasma turbulence on profiles of electron drift velocity in the equatorial electrojet. An experimental study. J. Geophys. Res., 99, 19549 19554, 1994.

Kudeki, E., Fejer, B, G., Farley, D. T., and Hanuise, C.: The CONDOR equatorial electrojet campaign: Radar results. J. Geophys. Res., 92, 13 561-13 577, 1987.

Manju, G.: Studies on equatorial electrojet. Ph.D. Thesis, University of Kerala, India, 44-54, 1997.
Pfaff, R. F., Kelley, M. C., Kudeki, E., Fejer, B, G., and Baker, K. D.: Electric field and plasma density measurements in the strongly driven daytime equatorial electrojet, 2. The unstable layer and gradient drift waves. J. Geophys. Res., 92, 13, 597612, 1987.

Prakash, S., Subbaraya B. H., and Gupta, S. P.: Rocket measurements of ionisation irregularities in the equatorial ionosphere at Thumba and identification of plasma irregularities. Indian J. Radio Space Phys., 1, 72-79, 1972.

Reddy, C. A., Vikramkumar, B. T., and Viswanathan, K. S.: Electric fields and currents in the equatorial electrojet deduced from VHF radar observations - I. A method of estimating electric fields. J. Atmos. and Terr. Phys., 49, 183-191, 1987.

Richmond, A. D.: Equatorial electrojet-I. Development of a model including winds and instabilities. J. Atmos. Terr. Phys., 35, 1083-1103, 1973a.

Richmond, A. D.: Equatorial electrojet-II. Use of the model to study the equatorial ionosphere.J. Atmos. Terr. Phys., 35, 11051118, 1973b.

Ronchi, C., Sudan, R. N., and Similon, P. L.: Effect of short scale turbulence on kilometre wavelength irregularities in the equatorial electrojet. J. Geophys. Res., 95, 189-200, 1990.

Ronchi, C., Sudan, R. N., and Farley, D. T.: Numerical simulations of large-scale plasma turbulence in the daytime equatorial electrojet. J. Geophys. Res., 96, 21 263-21 279, 1991.

Sudan, R. N.: Unified theory of type I and type II irregularities in the equatorial electrojet. J. Geophys. Res., 88, 4853-4860, 1983 a.

Sudan, R. N.: Non-linear theory of type I irregularities in the equatorial electrojet. Geophys. Res. Lett., 10, 983-986, 1983b.

Sudha R. and Reddy, C. A.: Variation of type I plasma wave phase velocity with electron drift velocity in the equatorial electrojet. J. Geophys. Res., 98, 21 581-21 592, 1993.

Vikramkumar, B. T., Viswanathan, K. S., and Rao, P. B.: VHF backscatter radar observations of the equatorial electrojet irregularities: Diurnal, seasonal and solar cycle variations. Ann. Geophys., 2, 495-500, 1984.

Viswanathan, K. S., Vikramkumar, B. T., and Reddy, C. A.: Electric fields and currents in the equatorial electrojet deduced from VHF radar observations, II. Characteristics of electric fields on quiet and disturbed days. J. Atmos. and Terr. Phys., 49, 193-200, 1987. 